\title{
O estudo do cálculo de área de figuras planas baseado em estratégia de resolução de problemas matemáticos
}

\author{
Joenneyres Raio de Souza Amâncio ${ }^{1}$ \\ Universidade Federal de Alagoas - UFAL
}

\section{Carloney Alves de Oliveira ${ }^{2}$}

Universidade Federal de Alagoas - UFAL

\begin{abstract}
RESUMO
O estudo aqui apresentado é fruto de uma pesquisa de mestrado vinculada ao Programa de Pós-Graduação em Ensino de Ciências e Matemática (PPGECIM/UFAL) com o objetivo de analisar, no contexto das aulas de Matemática do Ensino Fundamental, a possibilidade de se desenvolver práticas de aprendizagem de áreas de figuras planas, baseada em problemas. Trata-se de uma pesquisa qualitativa que adotou como método a pesquisa-intervenção, e participaram desse estudo 19 alunos de uma escola privada localizada no sertão alagoano. Como dispositivos para coleta de dados utilizamos a observação participante, atividades de resolução de problemas e entrevistas. Os resultados revelaram que os sujeitos, ao refletir sobre suas práticas e resoluções, vislumbraram a possibilidade transformá-las a partir das contribuições teórico-metodológica da Aprendizagem Baseada em Problemas (ABP), configurando como possibilidades e maneiras de aprender sobre área de figuras planas, pela interação e colaboração dos sujeitos envolvidos nesse estudo.
\end{abstract}

Palavras-chave: Aprendizagem Baseada em Problemas; Área de figuras planas; Estratégias de resolução de problemas.

\section{The study of the calculation of the area of flat figures based on a mathematical problem solving strategy}

\begin{abstract}
The study presented here is the result of a master's research linked to the Graduate Program in Science and Mathematics Teaching (PPGECIM/UFAL) with the aim of analyzing, in the context of Mathematics classes in Elementary School, the possibility of developing problem-based learning practices of flat figure areas. This is qualitative research that adopted intervention research as a method, and 19 students from a private school
\end{abstract}

${ }^{1}$ Mestre em Ensino de Matemática pelo Programa de Pós-graduação em Ensino de Ciências e Matemática da Universidade Federal de Alagoas. Endereço para correspondência: Avenida Martins Vieira, 753, Santana do Ipanema, Alagoas, Brasil, CEP: 57500-000. ORCID: https://orcid.org/0000-0002-4395-3384. E-mail: rd-raio@hotmail.com

${ }^{2}$ Doutor em Educação pela Universidade Federal de Alagoas - UFAL. Professor adjunto da Universidade Federal de Alagoas - UFAL, Maceió, Alagoas, Brasil. Endereço para correspondência: Rua Hélio Pradines, 766, Edifício Monte Humanari, Ponta Verde, Maceió, Alagoas, Brasil, CEP: 57035-220. ORCID: https://orcid.org/0000-0002-2134-0587. Email: carloneyalves@gmail.com

Revista de Educação Matemática (REMat), São Paulo (SP), v. 19, n. 01, p. 1-24, e022012, 2022, eISSN: $2526-9062$

DOI: $10.37001 /$ remat25269062v19id660 
located in the interior of Alagoas participated in this study. As data collection devices we use participant observation, problem solving activities and interviews. The results revealed that the subjects, when reflecting on their practices and resolutions, glimpsed the possibility of transforming them from the theoreticalmethodological contributions of Problem-Based Learning (PBL), configuring as possibilities and ways of learning about the area of flat figures, by the interaction and collaboration of the subjects involved in this study.

Keywords: Problem-Based Learning; Flat figures area; Problem solving strategies.

\title{
El estudio del cálculo del área de figuras planas basado en una estrategia de resolución de problemas matemáticos
}

\begin{abstract}
RESUMEN
El estudio que aquí se presenta es el resultado de una investigación de maestría vinculada al Programa de Posgrado en Enseñanza de las Ciencias y las Matemáticas (PPGECIM / UFAL) con el objetivo de analizar, en el contexto de las clases de Matemática en la Educación Primaria, la posibilidad de desarrollar prácticas de aprendizaje de problemas. -áreas de figuras planas basadas en. Se trata de una investigación cualitativa que adoptó la investigación de intervención como método, y 19 estudiantes de una escuela privada ubicada en el interior de Alagoas participaron en este estudio. Como dispositivos de recopilación de datos utilizamos la observación participante, las actividades de resolución de problemas y las entrevistas. Los resultados revelaron que los sujetos, al reflexionar sobre sus prácticas y resoluciones, vislumbraron la posibilidad de transformarlas a partir de los aportes teórico-metodológicos del Aprendizaje Basado en Problemas (ABP), configurándose como posibilidades y formas de aprendizaje sobre el área de aprendizaje. cifras, por la interacción y colaboración de los sujetos involucrados en este estudio.
\end{abstract}

Palabras clave: Aprendizaje basado en problemas; Área de figuras planas; Estrategias de resolución de problemas.

\section{INTRODUÇÃO}

O ensino da Matemática por vez é visto como algo inalcançável pelos estudantes, visto como mérito de poucos e fracasso de muitos, entretanto essa visão vem sendo transformadas nos últimos anos, isso pode ser observado na medida em que professores de Matemática começa a investigar e inserir metodologias que possam proporcionar o entendimento de forma diferenciada e a participação de todos os envolvidos nesse processo de aprendizagem.

Nesse sentido, podemos observar os avanços da inserção das metodologias ativas no contexto educacional, no qual tem a finalidade de proporcionar o desenvolvimento de alunos ativos e participativos na construção do conhecimento. Em nosso estudo abordaremos a Aprendizagem Baseada em Problemas (ABP) como um dos recursos que podem servir de 
meios para que professores possam inovar nos processos de ensino e aprendizagem, em especial, na disciplina de Matemática com o conteúdo de áreas de figuras planas.

Frente a essas possibilidades, emergiu o seguinte problema de pesquisa: Como a ABP pode contribuir na compreensão do conteúdo de áreas de figuras planas nas aulas de Matemática de alunos do $6^{\circ}$ ano do Ensino Fundamental de uma escola privada localizada no município de Olho D'Água das Flores, no sertão alagoano? Para alcançarmos o resultado desse questionamento buscamos elencar como objetivo geral: analisar, no contexto das aulas de Matemática do Ensino Fundamental, a possibilidade de se desenvolver práticas de aprendizagem de áreas de figuras planas, baseada em problemas.

Este estudo, de abordagem qualitativa, fundamentado nos estudos de Flick (2009), configura-se como uma pesquisa-intervenção (GALVÃO e GALVÃO, 2017) que tem um importante papel de atuar junto com a resolução de problemas na medida em que atua diretamente no campo pesquisado e que seus participantes atuarão de forma ativa e participativa nas resoluções de problemas, sabendo conviver com diferentes opiniões, possibilidades e estratégias.

A escola escolhida para o desenvolvimento da pesquisa foi cenário de interações e contou com a participação de 19 alunos do $6^{\circ}$ ano dos anos iniciais do Ensino Fundamental, turno vespertino. Os dados foram produzidos a partir da observação participante, atividades de resolução de problemas e entrevistas. Mantivemos o princípio ético da pesquisa, tendo sido submetida e aprovada no Comitê de Ética da UFAL sob o número CAAE: 18216619.5.0000.5013, buscando o anonimato dos sujeitos pesquisados.

A partir dessas considerações iniciais, o artigo segue organizado em três seções. $\mathrm{Na}$ próxima seção, apresentamos algumas concepções sobre o ensino de áreas de figuras planas, em diálogo com a ABP. Posteriormente, tratamos sobre o caminho metodológico da pesquisa e seus elementos. Em seguida, apresentamos os resultados, acompanhados das suas análises e interpretações. Por fim, concluímos então com algumas considerações acerca da pesquisa e suas implicações para a área de Educação Matemática. 


\section{O ENSINO DE ÁREA DE FIGURAS PLANAS NA PERSPECTIVA DA ABP}

O ensino da Geometria vem sendo discutido desde os primórdios dos tempos, quando surgiram as necessidades de divisões de terras, construção de casas e de outras situações do dia a dia que necessitavam do uso da geometria plana. Essas situações podem ser observadas com os povos antigos a exemplo dos gregos em suas construções dando suas contribuições para a geometria que hoje é estudada nas escolas.

A geometria plana está ligada aos seguintes conteúdos: ponto, reta e plano; posição relativa entre retas e planos; ângulos e medidas; formas e medidas no qual podem ser observados em nosso cotidiano nas diversas representações, por exemplo: na natureza, na arquitetura dos espaços, na arte, nessa perspectiva é possível verificar que a geometria visa estudar as formas e os espaços. Como afirmam Clemente et al. (2015, p.3)

Por meio da exploração das formas geométricas, o aluno desenvolve a percepção
do mundo em que está inserido, descreve-o, representa-o e aprende a localizar-se
nele. O trabalho com as noções geométricas deve instigar os educandos a serem
observadores, a perceberem semelhanças e diferenças e a identificarem
regularidades. Dessa forma, a geometria pode apresentar-se para a criança de
forma prática. Ela constrói suas primeiras noções espaciais por meio dos sentidos
e dos movimentos. Essa construção ocorre de forma gradual e tem como início a
percepção do próprio corpo, a presença no mundo e o seu redor. Somente em um
momento posterior, a criança atinge a compreensão do espaço representado em
desenhos, mapas e outras configurações.

Nesse ponto de vista, o ensino da geometria visa situar os alunos a compreender o espaço que habita, desenvolvendo no sujeito o pensamento crítico e reflexivo no momento em que analisam os espaços que estão inseridos fazendo, referência ao conteúdo de geometria em especial formas e medidas. Para Clemente et al. (2015) “O pensamento geométrico desenvolve-se inicialmente pela visualização: a criança é capaz de identificar uma figura apenas por sua forma, aparência física e geral e, enfim, por sua imagem”.

Partindo dessas ideias, observamos a importância de agregar aos cenários educacionais situações que levem os alunos a buscar compreender as coisas, em especial, as que estão ao seu redor podendo, associando aos conteúdos que estão sendo trabalhados. A geometria plana, por sua vez, busca orientar os alunos a respeito das áreas de figuras planas, nesse sentido buscamos observar esse conteúdo por fazer parte das situações do cotidiano 
dos nossos alunos. Essa prática de reconhecimento das formas geométricas no espaço em que habitamos relaciona-se das simples as mais complexas atividades que são desenvolvidas no dia a dia de cada indivíduo, tais como em medir um terreno para uma construção, para essa atividade precisamos compreender as formas geométricas (quadrado, retângulo, triângulo, losango e trapézio) para podemos compreender seu formato. E nessa perspectiva, ao relacionarmos esse conteúdo a situações problemas do dia a dia, precisamos compreender quais os procedimentos de resolução utilizadas pelos alunos nos momentos que estão frente a essa situação.

A partir desse contexto, entendemos que a $\mathrm{ABP}$ vem ganhando espaço nas instituições de ensino superior, graduação e pós-graduação, e em algumas disciplinas da educação básica segundo pesquisadores da área como: Munhoz (2018), Ribeiro (2010) e Pinheiro, Andrade e Júnior (2019). Para Barrows e Tamblyn (1980), a ABP tem como base utilizar problemas para aquisição de novos conhecimentos e de aprimorar os já adquiridos. Esse método de aprendizagem encontra-se centrado no aluno, sendo os professores facilitadores na apropriação dos conteúdos, com isso, os problemas são estímulos para desenvolver o pensamento crítico no momento das resoluções, ou seja, situações como essas podem ser observadas nos momentos em que os alunos estão resolvendo situações problemas do dia a dia, podendo surgir hipóteses e diferentes maneiras de resolução daquela situação. Como apresenta a Figura 1 a seguir:

Figura 1 - Área de um terreno

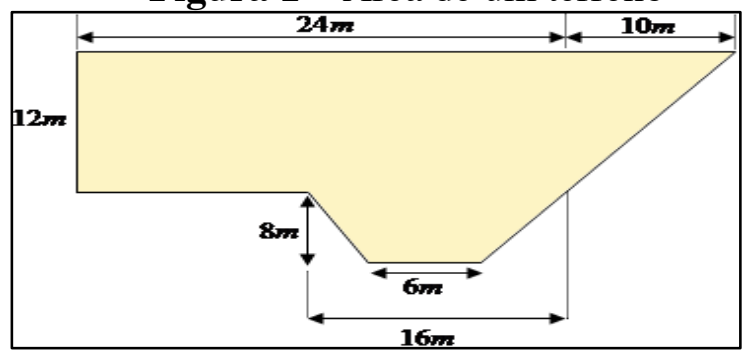

Fonte: http://professormarcelobr.blogspot.com/2012/07/matematica-aula-22-area-de-figuras.html

A partir dessa figura deseja-se que os alunos descubram a área desse terreno, com isso espera-se que os alunos ao observar façam os seguintes questionamentos: 
1- Como vou calcular a área dessa figura se não estudamos uma forma desse tipo?

2- Será possível dividir essa imagem em outras formas geométricas?

3- Como poderemos dividir essa imagem em outros formas geométricas?

4- Quais outras formas geométricas são formadas a partir dessa divisão?

5- Há uma maneira de encontrar a área das novas formas que foram encontradas?

6- Como ocorreria esses procedimentos?

7- O que fazemos para chegar ao resultado final?

A princípio, em uma situação hipotética, após análise feita pelos alunos, espera-se que cheguem a divisão da imagem dessa forma como mostra a figura 2 apresentada a seguir:

Figura 2 - Divisão da figura 1

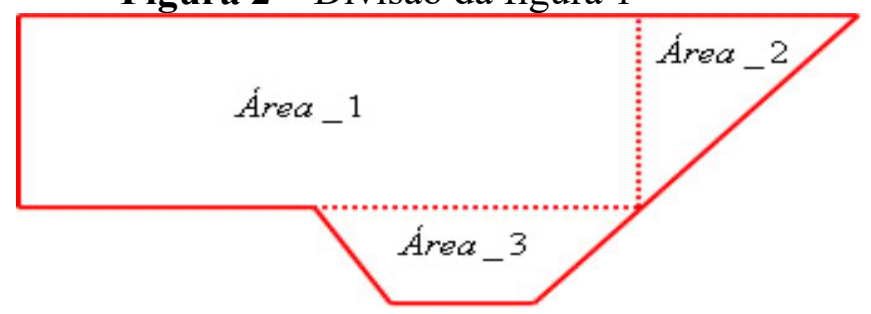

Fonte: http://professormarcelobr.blogspot.com/2012/07/matematica-aula-22-area-de-figuras.html

Diante da situação apresentada e feita a divisão da figura 2 em formas geométricas os alunos conseguem desenvolver a forma de cada área de uma figura plana chegando ao resultado da área total do terreno em análise, situações como essa podem ser desenvolvidas individualmente ou em grupo podendo ter a interação dos envolvidos para chegar a um resultado.

Para Van de Walle (2001) citado por Onuchic e Allevato (2011, p.10):

Um problema é definido como qualquer tarefa ou atividade para a qual não se tem métodos ou regras prescritas ou memorizadas, nem a percepção de que haja um método específico para chegar à solução correta. Para nós é tudo aquilo que não se sabe fazer, mas que se está interessado em fazer.

Nessa perspectiva, ao trabalhar com a resolução de problemas espera-se do professor novas posturas em sala de aula, escolhendo de forma apropriada os problemas que serão disponibilizados de modo a proporcionar a autonomia dos alunos no momento de resolução como afirmam Onuchic e Allevato (2011, p.11): 
O professor precisa preparar, ou escolher, problemas apropriados ao conteúdo ou ao conceito que pretende construir. Precisa deixar de ser o centro das atividades, passando para os alunos a maior responsabilidade pela aprendizagem que pretendem atingir. Os alunos, por sua vez, devem entender e assumir essa responsabilidade. Esse ato exige de ambos, portanto, mudanças de atitude e postura, o que, nem sempre, é fácil conseguir.

Ainda, na abordagem das pesquisadoras Onuchic e Allevato (2011, p.11), na qual cita algumas vantagens da mudança dessas posturas e seus benefícios que aqui apresentamos a seguir:

- Resolução de problemas coloca o foco da atenção dos alunos sobre as ideias matemáticas e sobre o dar sentido.

- Resolução de problemas desenvolve poder matemático nos alunos, ou seja, capacidade de pensar matematicamente, utilizar diferentes e convenientes estratégias em diferentes problemas, permitindo aumentar a compreensão dos conteúdos e conceitos matemáticos.

- Resolução de problemas desenvolve a crença de que os alunos são capazes de fazer matemática e de que a Matemática faz sentido; a confiança e a auto-estima dos estudantes aumentam.

- Resolução de problemas fornece dados de avaliação contínua, que podem ser usados para a tomada de decisões instrucionais e para ajudar os alunos a obter sucesso com a matemática.

- Professores que ensinam dessa maneira se empolgam e não querem voltar a ensinar na forma dita tradicional. Sentem-se gratificados com a constatação de que os alunos desenvolvem a compreensão por seus próprios raciocínios.

- A formalização dos conceitos e teorias matemáticas, feita pelo professor, passa a fazer mais sentido para os alunos.

Ao trabalharmos com aprendizagem centrada no aluno, verifica-se a importância da ABP, no desenvolvimento de atividade educacional que envolva a participação individual ou em grupos para discursões críticas e reflexivas, sendo possível permitir a convivência com diversas opiniões, transformando as atividades desenvolvidas em sala de aula em situações que envolvam a participação ativa dos alunos para elaboração do conhecimento, proporcionando diversidade na maneira de aprender.

Para Ribeiro (2010, p. 14):

A implantação da ABP no contexto educacional original veio em resposta à insatisfação e ao tédio dos alunos frente ao grande volume de conhecimento percebidos como irrelevantes à prática médica. Esta iniciativa também foi decorrente do fato de seus formandos estarem deixando o curso com muitos conceitos, mas com poucas estratégias e poucos comportamentos associados à aplicação de informações a um diagnóstico.

Segundo o autor citado, o papel da ABP é colocar o aluno no centro da aprendizagem, colocando em contato com a realidade profissional desde o primeiro ano de curso, com isso 
a aprendizagem pode ser mais proveitosa quando se adapta a uma realidade da sociedade em seus problemas do dia a dia.

Segundo Munhoz (2018, p. 124):

\begin{abstract}
A aprendizagem que se adapta ao contexto de uma nova sociedade onde as mudanças acontecem de forma abrupta e emergencial altamente acelerado e imprevisível em seu desenvolvimento parece encontrar na ABP uma nova maneira de engajar os alunos e formar egressos com competências e habilidades mais próximas do que aquilo que o mercado exige.
\end{abstract}

Conforme o autor, os avanços vivenciados pela sociedade contemporânea encontram na ABP uma nova maneira de envolver os estudantes nas situações problemas do cotidiano, por exemplo medir a área de uma determinada região, desenvolvendo nos envolvidos capacidades de atuar nas diversas situações que serão postas pela sociedade.

A ABP busca colocar os alunos frente a situações problemas do dia a dia, buscando tornar os mesmos ativos no processo de ensino e aprendizagem. Com utilização da ABP pode-se verificar mudanças na cultura dos envolvidos, ou seja, os alunos saem do polo passivo da aprendizagem tornando sujeito ativo na construção do conhecimento na medida em que soluciona situações do dia a dia. A seguir, apresentamos o Quadro 1 com as características do modelo tradicional e do modelo ABP.

Quadro 1 - Características modelo tradicional e ABP

\begin{tabular}{|c|c|c|}
\hline Parâmetros & Método tradicional & Método ABP \\
\hline Aluno & Receptor das informações & Ativo na construção do conhecimento \\
\hline Professor & Emissor das informações & Facilitador / Orientador / Mediador \\
\hline Ambiente & Competitivo e excludente & Colaborativo \\
\hline Aprendizagem & $\begin{array}{l}\text { Memorização e reprodução das } \\
\text { informações }\end{array}$ & Raciocínio e descoberta \\
\hline Organização da sala & Fileiras & Equipes de estudantes \\
\hline Problemas & $\begin{array}{l}\text { Após emissão do conteúdo pelo } \\
\text { professor }\end{array}$ & $\begin{array}{l}\text { Posto como desafio inicial que motiva } \\
\text { e desenvolve a criticidade ampliando } \\
\text { o conteúdo }\end{array}$ \\
\hline Aulas & Expositivas & Diálogo \\
\hline Metodologia & $\begin{array}{l}\text { Transmissão dos conteúdos } \\
\text { estruturados na maioria das vezes pelos } \\
\text { livros didáticos }\end{array}$ & $\begin{array}{l}\text { Ativa, aproveitando os conhecimentos } \\
\text { prévios dos estudantes para obtenção } \\
\text { dos novos conhecimentos }\end{array}$ \\
\hline
\end{tabular}




\begin{tabular}{|l|l|l|}
\hline Avaliação & $\begin{array}{l}\text { Produto da reprodução dos conteúdos } \\
\text { ministrado pelo professor, conteúdos } \\
\text { decorados e reproduzidos }\end{array}$ & $\begin{array}{l}\text { Processual, privilegiando a tomada de } \\
\text { decisões individuais e em grupos }\end{array}$ \\
\hline Consequência & $\begin{array}{l}\text { Alunos reprodutores dos conteúdos } \\
\text { emitidos pelos professores }\end{array}$ & $\begin{array}{l}\text { Alunos críticos, capazes de solucionar } \\
\text { problemas apresentados pelo } \\
\text { cotidiano. }\end{array}$ \\
\hline
\end{tabular}

Fonte: Adaptado a partir de Ribeiro (2019, p.33) e Ribeiro (2005, p.48)

A partir das observações apresentadas no Quadro 1, podemos notar a diferença no momento de atuação entre a sala de aula tradicional e a sala com a aprendizagem baseada em problemas, mostrando suas principais características, aspectos fundamentais, comparando os parâmetros em cada situação de desenvolvimento das duas metodologias em análise. Diante das características apresentadas pela ABP, acreditamos que as instituições de ensino podem repensar sua atuação na sociedade, proporcionando aos alunos pensar de forma crítica, participativa, colaborativa e reflexiva no momento em que precisam tomar decisões para resolução do problema, observando que cada aluno pode ter uma maneira diferente de chegar ao resultado desejado.

Diante do cenário apresentado pelo $\mathrm{ABP}$ os papeis dos envolvidos apresentam mudanças em suas culturas, ou seja, os alunos estão acostumados a receber informações estruturadas pelo professor, como é visto no modelo tradicional de ensino, no qual professor é o detentor do conhecimento trabalhando com uma postura reprodutivista do conhecimento.

Para Munhoz (2018, p.28):

Nesse ambiente acontecem mudanças na cultura mais ou menos profundas. A
primeira mudança cultural que podemos identificar se manifesta quando os alunos
enfrentam um ambiente colaborativo. Eles são colocados perante o desafio de
aprender que não estão mais sozinhos e que fazem parte de um grupo, da mesma
forma como as coisas acontecem nas organizações do mercado contemporâneo, na
vida real, [...], em grupo, um aluno não é levado a conduzir todas as pesquisas e
apresentar soluções do problema.

Nesse sentido, conforme o autor, um dos grandes impactos apresentados na ABP está na relação dos envolvidos, no qual poderá trabalhar em grupos, desenvolvendo funções específicas para crescimento da equipe. As mudanças também são visíveis no papel do professor, ele é instigado a ignorar a postura adotada no método tradicional assumindo a função de facilitador, orientador e mediador, como mostra o quadro 1, do processo de ensino 
e aprendizagem, aceitando a possibilidade de aprender junto com os alunos e que as formulações apresentadas pelos alunos podem ocorrer de maneiras diferentes das rotineiras dos professores, ou seja, os alunos podem apresentar soluções diferentes do professor, que na maioria das vezes, na área da Matemática, acontecem com apresentações de fórmulas préestabelecidas.

Nos ambientes da ABP o professor passar a ter um papel de facilitador da aprendizagem, levando questionamentos para os estudantes para conduzi-los a chegar a uma possível solução do problema apresentado. Ao trabalhar com a ABP o professor irá assumir um papel de facilitador, orientador e mediador no processo de ensino e aprendizagem, saindo do seu patamar de detentor do conhecimento, podendo aceitar as diversas formar de solução dos problemas.

Nesse cenário da ABP o aluno terá um papel ativo na construção do seu conhecimento, podendo utilizar dos conhecimentos prévios para chegar a um estágio mais avançado do conhecimento, a partir das resoluções dos problemas orientados e mediados pelo professor. O Quadro 2 a seguir apresenta as vantagens para os alunos, segundo Munhoz (2018):

Quadro 2 - Vantagens da ABP

Algumas das vantagens para o aluno com utilização da ABP

1- A ABP oferece ao aluno a possibilidade de adquirir um conhecimento com maior durabilidade.

2- O trabalho desenvolvido na ABP leva os alunos a planejar e organizar de forma mais cuidadosa diversos aspectos: o tempo gasto, o local de aprendizagem, escolha dos locais de pesquisa, seleção de informações, validação de informações e a sua utilização para resolver problemas que, junto com seu grupo, foi determinado como necessário para aprendizagem.

3- O desenvolvimento da capacidade de autoavaliação é uma das grandes vantagens. Os alunos analisam o trabalho antes de entregar e se surpreendem ao cumprir os objetivos sem que coerção ou punição estejam previsto em casos de erro. O aprender pelo erro é parte é parte componente do processo de avaliação em ABP.

4- Os alunos e professores se aproximam muito mais, e é possível perceber a recuperação da afetividade no relacionamento entre esses participantes.

$$
\text { Fonte: Munhoz (2018, p. 176) }
$$

Com a visualização do Quadro 2 é possível verificar algumas das vantagens apresentadas durante a utilização da ABP por parte dos alunos segundo Munhoz (2018). Nesse perspectiva, acreditamos que a utilização da ABP em nossa pesquisa é pertinente pois buscamos desenvolver nos alunos sua participação ativa, ou seja, quando os alunos se dedicam aos estudos, participam de pesquisas a respeito do tema, buscam outras fontes de 
informações, aprende a partir de outros meios como jogos, vídeos ou até mesmo quando estão produzindo um jogo que esteja associado ao conteúdo trabalhado e na utilização de materiais manipuláveis; sabendo administrar seu tempo, se auto avaliar, participar de tomadas de decisões em grupos e a participação afetiva entre alunos/alunos e alunos/professor.

\title{
METODOLOGIA
}

A importância da metodologia para o desenvolvimento da pesquisa surge no sentido de ser um processo criativo que dever ser explorado na busca para compreender os fenômenos que possam surgir no decorrer do desenvolvimento do estudo, sejam eles a favor ao seu objeto ou não, como afirma Oliveira (2015, p.100):

\begin{abstract}
A pesquisa como um processo criativo deve ser identificada pela exploração e identificação de múltiplas perspectivas que buscam a compreensão do fenômeno, sejam elas positivistas, construtivistas, interacionistas ou outras, implicando habilidades metodológicas mínimas em termos de saber montar propostas dotadas de alguma cientificidade, em particular a capacidade de argumentar.
\end{abstract}

O papel da metodologia na condução da pesquisa, além de estudar os métodos, é conduzir os passos da pesquisa para alcance dos objetivos previamente desejáveis. Adotamos como tipo de pesquisa a qualitativa por entender que esse método tenta descobrir uma realidade, mas não mediante o tratamento estatístico das variáveis. Por meio dele, os resultados não são generalizados, em vez disso, ocorre à exploração e a descrição mais profundas de fenômenos, Sampieri; Collado; Lucio, (2013). Para Flick (2009, p,37) que “A pesquisa qualitativa se dirige à análise de casos concretos em suas peculiaridades locais e temporais, partindo das expressões e atividades das pessoas em seus contextos locais".

Para Creswell (2010, p. 206),

\begin{abstract}
os métodos qualitativos mostram uma abordagem diferente da investigação acadêmica do que aquela dos métodos da pesquisa quantitativa. A investigação qualitativa emprega diferentes concepções filosóficas; estratégias de investigação; e métodos de coleta de dados, análise interpretação dos dados. Embora os processos sejam similares, os procedimentos qualitativos baseiam-se em dados de textos e imagem, têm passos singulares na análise dos dados e se valem de diferentes estratégias de investigação.
\end{abstract}


Adotamos em nossa pesquisa o método investigativo da pesquisa-intervenção, pois tem como finalidade conviver com diferentes opiniões como afirma Galvão e Galvão (2017, p.8):

\begin{abstract}
A pesquisa intervenção pressupõe saber ouvir e conviver com o diferente, desenvolver atividades que possam constituir-se em acontecimentos analisadores, enfrentar os próprios limites e medos; registrar cada passo, cada reação e cada fala são processos importantes na coleta de dados. Outros desafios desse tipo de investigação constituem a capacidade de considerar as diferentes visões que ambientam o espaço da pesquisa, assim como, as posições divergentes, as aproximações e afastamentos, a necessidade de horizontalizar a relação pesquisador/participante do estudo, colocar em cheque a organização e as relações instituídas privilegiadas no espaço de investigação, somos também as implicações do pesquisador, suas escolhas.
\end{abstract}

A pesquisa foi realizada em uma escola privada localizada no município de Olho D’Água das Flores, situada no sertão alagoano. A distância do município para a capital do estado é de aproximadamente $206 \mathrm{~km}$. A escolha por esta instituição deu-se pelo fato do pesquisador ser colaborador da escola e ter autorização da direção, para o desenvolvimento da sua pesquisa e participaram desta pesquisa 19 alunos do $6^{\circ}$ ano do Ensino Fundamental, do turno vespertino, na oportunidade os que desejaram participar assinaram o Termo de Assentamento Livre e Esclarecido (TALE) e seus responsáveis o Termo de Consentimento Livre e Esclarecido (TCLE).

Para obtenção dos dados desejados, realizamos nossa pesquisa em quatro etapas, a seguir descritas:

Primeira etapa: desenvolvimento de questões sobre áreas de figuras planas com os alunos e nesse momento da pesquisa buscamos compreender mediante as resoluções feitas pelos alunos, quais foram as estratégias utilizadas no momento de resolução dos problemas. Nessa etapa da pesquisa, buscamos compreender como os alunos resolveriam as questões disponibilizadas, buscando compreender quais estratégias foram tomadas nos momentos das resoluções. Consideramos importante esse momento da pesquisa, pois foi por meio dessa etapa que verificamos como os alunos estavam em relação ao assunto abordado em nosso estudo.

Segunda etapa: resolução das questões da primeira etapa reestruturada com materiais manipuláveis. Podemos observar a importância dessa etapa da pesquisa no momento de verificar como os alunos resolveriam as questões a partir das suas modificações com 
utilização dos materiais manipuláveis, bem como verificar suas estratégias de resoluções dos problemas.

Terceira etapa: apresentação dos problemas produzidos pelos alunos, no qual buscou apresentar um problema da realidade que eles já tinham vivenciado. Essa etapa da pesquisa pode contribuir para analisarmos a elaboração de problemas pelos alunos, podendo observar sua criatividade e estratégias para criar os problemas.

Quarta etapa: será realizada uma entrevista semiestruturada, para analisar a experiência dos alunos durante o desenvolvimento desse estudo. As entrevistas contribuíram com nosso estudo na perspectiva de verificarmos, na visão dos alunos, as contribuições desse estudo para sua formação no qual deu autonomia para criação dos problemas, buscando proporcionar cada vez mais o protagonismo dos envolvidos, proporcionando o desenvolvimento de sujeitos ativos e participativos nas tomadas de decisões.

\section{RESULTADOS}

Os resultados aqui apresentados são um recorte da análise dos dados da pesquisa e buscamos elencar as estratégias, resoluções e a criatividade dos alunos ao longo do desenvolvimento do estudo e das questões problemas e seus procedimentos de resolução.

Segundo Junior e Onuchic (2015, p.5) "a criatividade atua como uma potência inerente aos agenciamentos e aos acontecimentos no pensamento dos estudantes, que ao se depararem com os problemas, buscarão meios para resolvê-los”. Nesse momento do estudo buscamos observar como os alunos se comportavam ao ser criadores dos problemas do dia a dia sendo protagonistas da aprendizagem, associando seus conhecimentos matemáticos com as situações do seu cotidiano.

A Figura 3 a seguir representa uma situação não contextualizada de uma questão que foi desenvolvida na primeira fase desse estudo. 
Figura 3 - Questão proposta

CEFET- MG (2016 adaptada) A área quadrada de um sítio deve ser dividida em quatro partes iguais, também quadradas, e, em uma delas, deverá ser mantida uma reserva de mata nativa (área hachurada), conforme mostra a figura a seguir. Sabendo-se que B é o ponto médio do segmento AE e C é o ponto médio

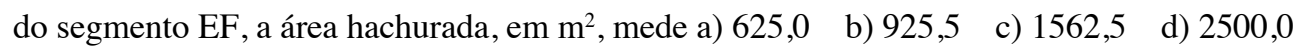

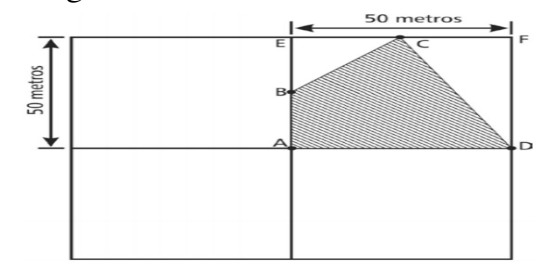

Fonte: Questão do CEFET - MG (2016)

Durante a resolução dessa questão os alunos relataram que estava difícil de compreender o que a situação estava querendo. A partir dessa situação em que os alunos não conseguiram responder a questão proposta o pesquisador reformulou a questão utilizando emborrachado e algumas figuras para representar alguns espaços de uma casa e apresentou novamente aos estudantes como pode ser visto na Figura 4 a seguir:

Figura 1 - Questão da primeira fase modificada

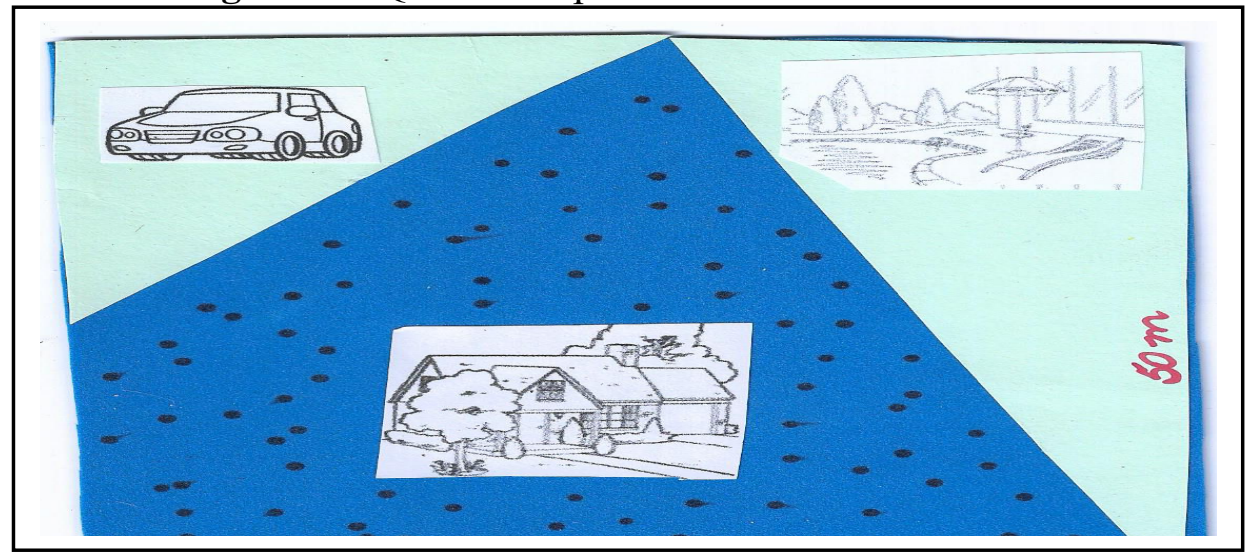

Fonte: Dados da pesquisa (2019)

Diante da situação apresentada na figura acima, os alunos demostraram interesse em resolver a situação proposta, por mais que não tivessem passos a serem seguidos, os alunos relataram que se sentiram desafiados diante da nova proposta. Essa situação, comunga com o pensamento de Van Walle (2001) citado por Onuchic e Allevato (2011, p.10) "que um problema é definido como qualquer tarefa ou atividade que não se tem métodos ou regras 
prescritas, para nós é tudo aquilo que não se sabe fazer, mas que se está interessado em fazer".

Nesse sentido, observamos que os alunos diante dessa situação, estavam desafiados a buscar uma solução para a questão em análise, instigados a observarem o desenho, observando suas particularidades e semelhanças. Para Clemente et al. (2015) o trabalho com as noções geométricas deve instigar os educandos a serem observadores, a perceberem semelhanças e diferenças e a identificar regularidades. Após, compreender o problema e executar seu planejamento foi possível verificar que o aluno A1 conseguiu verificar que as figuras vizinhas da área hachurada, tinha formato de dois triângulos, e desenvolveu sua resolução conforme Figura 5.

Figura 5 - Resolução da questão pelo aluno A1

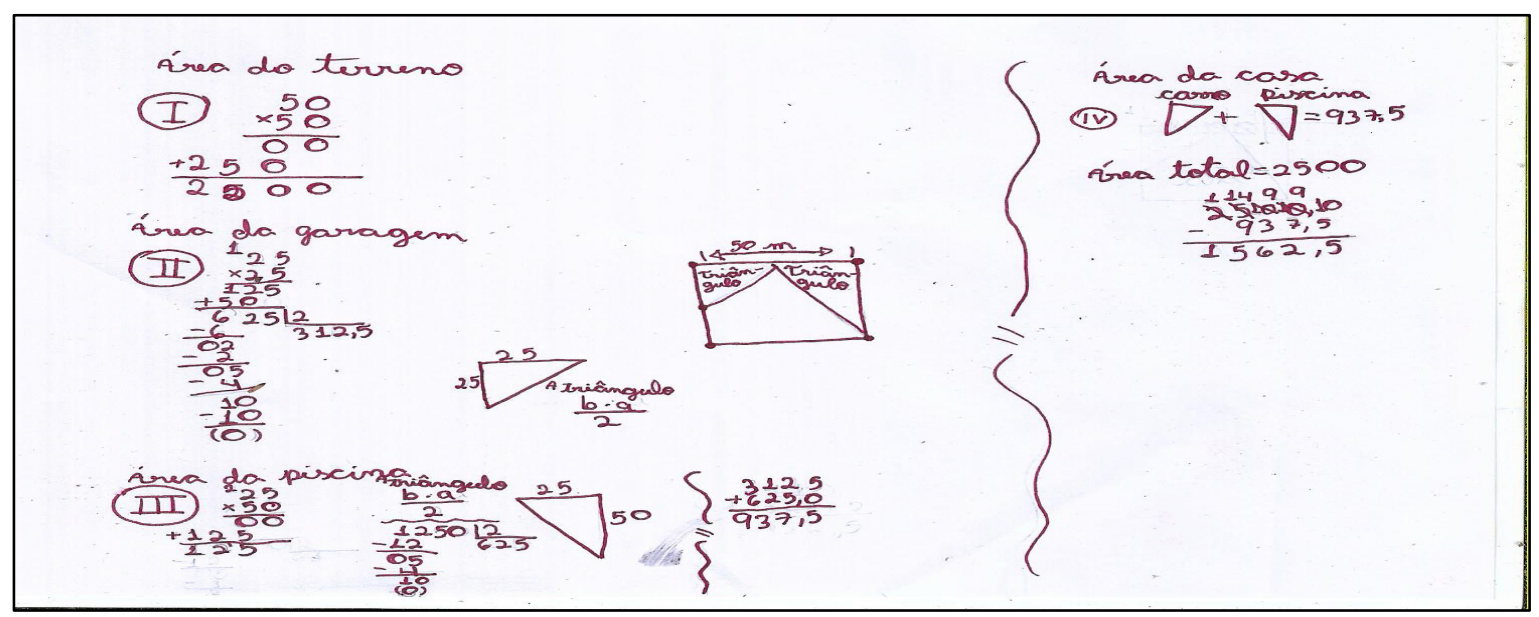

Fonte: Dados da pesquisa (2019)

Além disso, podemos observar a partir dessa análise que o aluno sabia a fórmula que representaria as regiões triangulares, bem como o aluno também compreendeu que a área total do terreno era em formato de um quadrado que continha dois triângulos e que para achar a área da casa era necessário subtrair as áreas triangulares (II e III), representado sua soma na figura (IV), da área do quadrado (I - terreno), isso pode ser relacionado a afirmação feita por Pinheiro, Andrade e Júnior (2019, p.23) quando afirmam que as situações devem ser contextualizada aproximando a vida acadêmica do cotidiano do aluno. Essa situação colabora com as ideias de Onuchic e Allevato (2011, p.11) que relata a "resolução de problemas desenvolve a crença de que os alunos são capazes de fazer matemática e de que 
a Matemática faz sentido; a confiança e a auto-estima dos estudantes aumentam" bem como a "resolução de problemas coloca o foco da atenção dos alunos sobre as ideias matemáticas e sobre o dar sentido".

No momento de criação das situações problemas os alunos foram divididos em grupos, no qual tinham que elaborar uma questão para representar o assunto que estava sendo trabalhado, ou seja, o conteúdo de áreas de uma figura plana. Essa ocasião foi dividida nas seguintes etapas: Elaboração das questões pelos alunos, eles montaram uma planta que representaria a situação da questão e no momento de ocasião de apresentar sua construção para turma como apresenta a Figura 6.

Figura 6 - Questão montada pelo grupo 2

1) No zoológico foi apresentado uma lei que para os animais se sentirem confortáveis em suas jaulas, deve-se medir $170 \mathrm{~m}^{22}$. Calcule a área delas. JDM: JDE: JDL: JDO: JDP: JDG: JDT: Alguma jaula não deteve $170 \mathrm{~m}^{2}$ ? Se sim, apresente uma solução para o problema. Calcule a área total do zoológico. Qual a área não ocupada pelas jaulas?

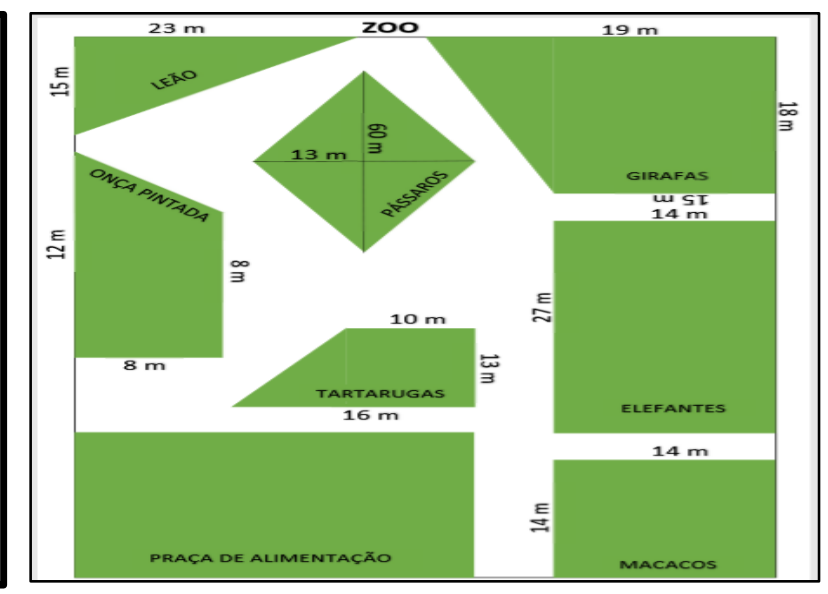

Fonte: Dados da pesquisa (2019)

Na Figura 6 que representa a questão elaborada pelo grupo dois podemos observar que a equipe utilizou todas as formas estudadas no conteúdo de área de uma figura plana, ou seja o quadrado $a=l \times l$, retângulo $a=b . h$, triângulo $a=\frac{b . h}{2}$, trapézio $a=\frac{(B+b) \cdot h}{2}$, losango $a=\frac{D . d}{2}$, isso pode ser observado na parte do leão onde podemos ver que a região representa um triângulo, o local dos pássaros que representa um losango, espaço das girafas, onça e tartaruga que representam a forma do trapézio, o espaço dos elefantes que representa o retângulo e o espalho dos macacos que representam o quadrado. Um detalhe a ser observado é que os alunos ao elaborarem essa questão colocou as iniciais para representar os espaços, ou seja, JDM é formado por JD (jaula do) + M (macaco) inicial de cada espaço. 
A finalidade de elaboração da maquete apresenta-se como representação da proposta idealizada, com o desejo de demonstrar a associação de situações reais ao conteúdo que estava sendo abordado. Essas abordagens podem ser observadas nas figuras descritas a seguir. A Figura 7 apresentada posteriormente representa o modelo da Figura 7.

Figura 7 - Maquete da questão do grupo 2

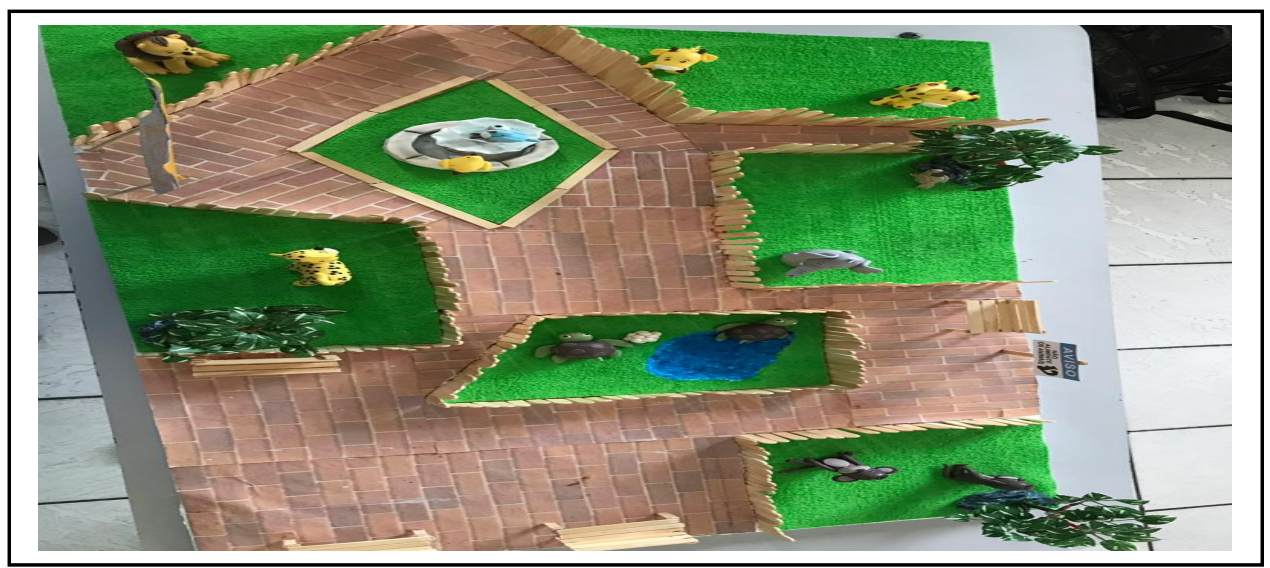

Fonte: Dados da pesquisa (2019)

Na Figura 7 podemos ver a imagem por cima dando uma visão geral do que os alunos representaram sua planta em forma de um zoológico. A seguir apresentamos as partes onde ficava cada animal como mostra as figuras a seguir.

Figura 8 - Área do espaço dos pássaros

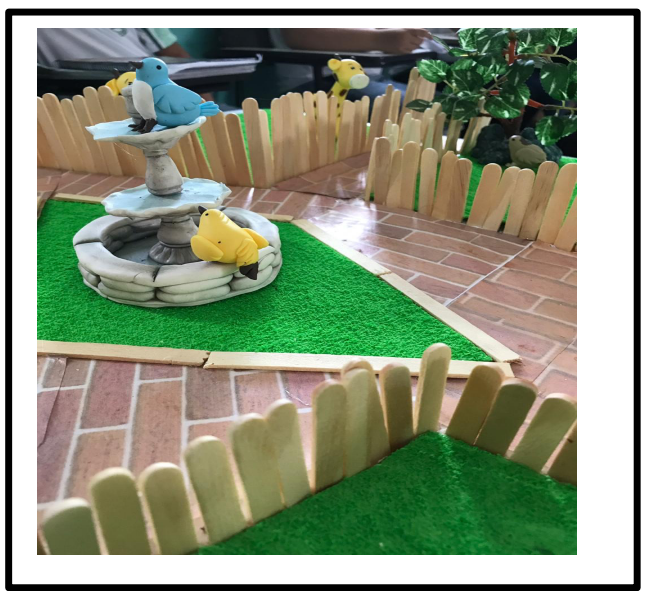

Fonte: Dados da pesquisa (2019)
Figura 9 - Área do espaço dos pássaros 2

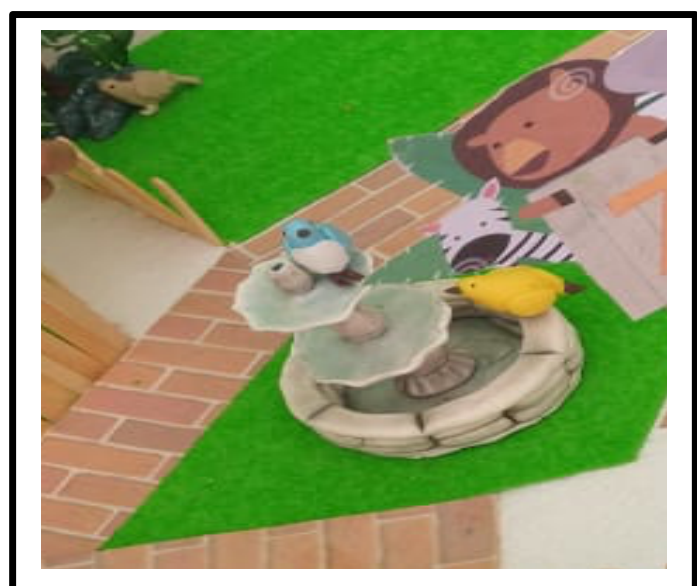

Fonte: Dados da pesquisa (2019) 
As Figuras 8 e 9 representam o local onde estava os pássaros, notamos que o espaço representado estava igual a representação da Figura 8 mostrando a área do losango, nessa perspectiva, o aluno para calcular a área dessa região precisa multiplicar sua diagonal maior pela diagonal menor e dividir por dois seguindo a fórmula Matemática $a=\frac{D . d}{2}$.

Observemos a Figura 10 que representa outra parte da maquete:

Figura 10 - Área do espaço do macaco

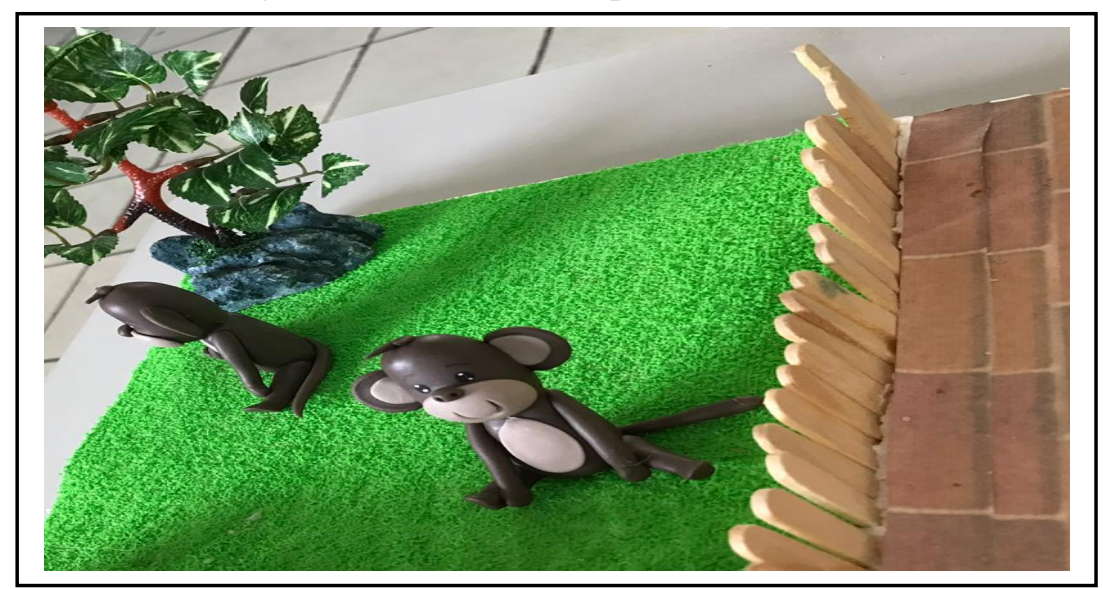

Fonte: Dados da pesquisa (2019)

Observamos na Figura 10 que a área ocupada pelos macacos representa um quadrado como estava previsto na questão proposta pelo grupo dois com a fórmula Matemática $a=$ $l \times l$. Para encontrar a área dessa região o estudante precisará multiplicar lado vezes lado. Observemos a Figura 11.

Figura 11 - Área do espaço das tartarugas

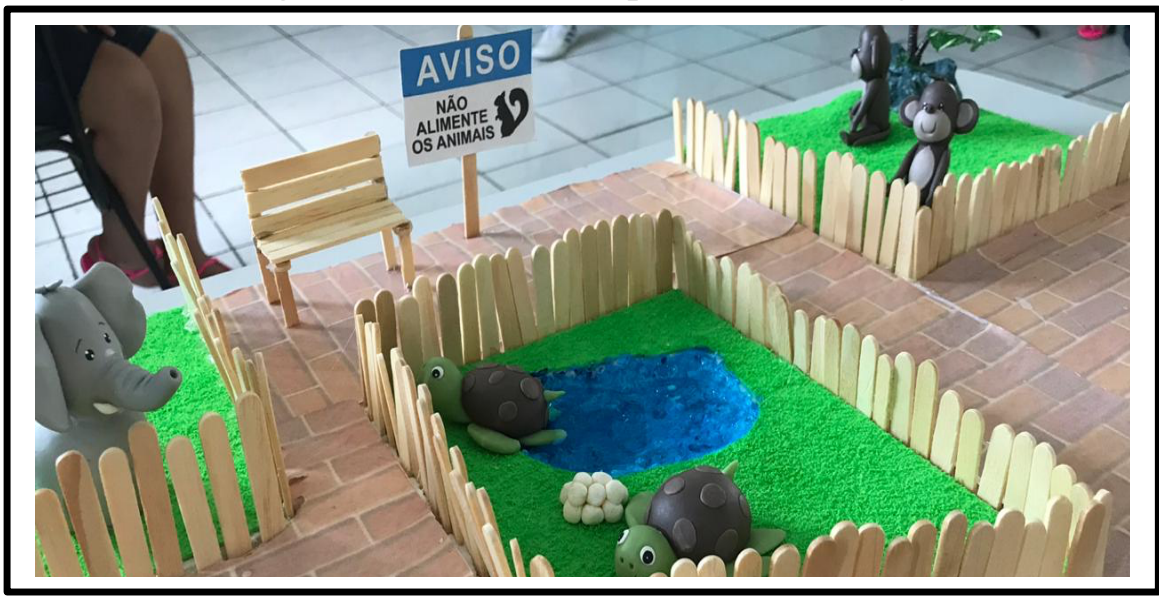

Fonte: Dados da pesquisa (2019) 
Nessa Figura 11 podemos observar a representação da área reservada para as tartarugas, que exibindo o formato de um trapézio, no qual o aluno para encontrar sua área deverá somar a base maior com a base menor depois multiplicar por sua altura e em seguida dividir por dois.

A Figura 12 exibe outra forma geométrica.

Figura 12 - Área do espaço dos elefantes

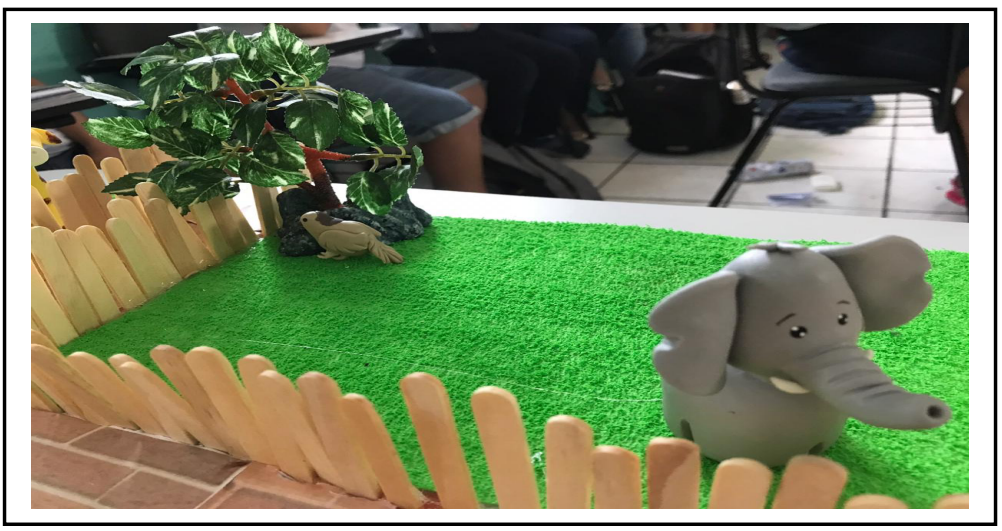

Fonte: Dados da pesquisa (2019)

Diante da Figura 12 podemos notar que os estudantes usaram da sua criatividade para representar o retângulo, local que nessa situação estava sendo pelo espaço dos elefantes. Nesse contexto, para encontrar a área ocupada pelo espaço do elefante os alunos precisaram calcular a base vezes altura. E para representar outra região geométrica observe a Figura 13.

Figura 13 - Área do espaço dos leões

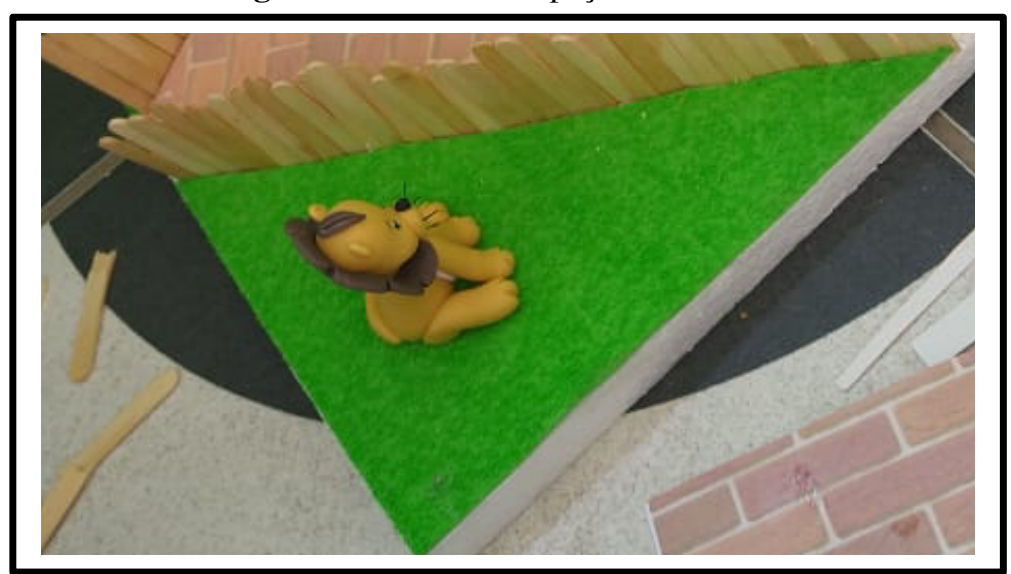

Fonte: Dados da pesquisa (2019)

Revista de Educação Matemática (REMat), São Paulo (SP), v. 19, n. 01, p. 1-26, e022012, 2022, eISSN: 2526-9062

DOI: $10.37001 /$ remat25269062v19id660

Sociedade Brasileira de Educação Matemática - Regional São Paulo (SBEM-SP) 
Nessa situação podemos verificar que os alunos representaram a região ocupada pelo leão em formato de triângulo e que para encontrar sua área precisaram multiplicar base vezes altura e dividir por dois. Diante desse contexto apresentado por essas figuras, observamos que os alunos fizeram uso da sua criatividade para montar questões do dia a dia relacionados aos conteúdos que estavam sendo tratados em sala de aula para poder aprender de forma criativa, como afirma Onuchic e Allevato (2011, p.11) a "resolução de problemas desenvolve poder matemático nos alunos, ou seja, capacidade de pensar matematicamente, utilizar diferentes e convenientes estratégias em diferentes problemas, permitindo aumentar a compreensão dos conteúdos e conceitos matemáticos”.

A partir da observação realizada nos problemas elaborados pelas duas equipes, podemos classificar esses dois problemas de acordo com Carvalho (2010) em problemas de leitura de imagem onde os problemas são apresentados e os alunos observam as plantas com os dados apresentados nas fórmulas geometrias e respondem as alternativas exibidas, também classificamos esses dois problemas como sendo completando o enunciado com diferentes perguntas sem a conta que para Carvalho (2010, p. 34) "Dá-se a situação problema e as possíveis perguntas.

A partir da pergunta escolhida, o aluno resolve o problema, de forma a torná-lo correto", ou seja, os alunos têm uma questão e a partir da sua observação resolve as alternativas que estão propostas. Ao concluirmos essa etapa do estudo, realizamos um questionamento para analisarmos a sensação que os alunos tiveram ao elaborar seus problemas, o questionamento foi o seguinte: $O$ que você achou de poder criar um problema/questão em grupo? Justifique sua resposta! Nessa situação da elaboração dos problemas, podemos proporcionar aos estudantes o sentido de alunos ativos e participativos na construção do seu conhecimento baseados nos estudos de Bergmann e Sams (2018) e Bacich, Neto e Trevisani (2015).

A1: Muito legal pois em vez da gente só responder nos tivemos que criar e corrigir cada uma das questões, mas quando víamos eles tentando resolver você sente um orgulho de si mesmo.

A2: Foi ótimo porque todo mundo interagiu e ficou muito bom de criar essa questão e é mais um aprendizado.

A3: Foi legal, pois nós podemos pensar juntos e fazer uma questão bem elaborada.

A4: Foi divertido, eu nunca vi um professor ou professora fazer assim, eu aprendi bastante gostei de montar a maquete só com o tema que a gente inventou, pausa na fala da aluna, e o que possa falar é um jeito mais fácil de aprender, mais divertido. Porque da pra aprender mais, o 
exemplo do zoológico, a gente fez o zoológico foi aprendendo área e consegui prestar mais atenção que nas aulas.

A5: Eu achei muito divertido, pois a gente aprendia fazendo na prática, nós fizemos nossa própria questão e cada um se ajudava como se fosse uma única pessoa, se um não sabia de alguma coisa o outro ajudava. Todo mundo ajudou numa certa coisa e a organização foi o melhor por causa que todos ajudaram e a gente se tornou mais um grupo porque antes os trabalhos em grupos aqui normalmente era só a gente se reunir e fazer o trabalho e vinha e apresentava, esse a gente teve que se reunir mais, debater mais, fazer nossas próprias questões.

Diante dos depoimentos e falas dos alunos podemos observar que a criação dos problemas pelo grupo foi importante para aprendizagem dos estudantes e união do grupo, isso mostra que a aprendizagem baseada em problemas na perspectiva do ensino híbrido pode proporcionar não somente a formação de alunos ativos e participativos na construção do conhecimento, mas, também, nos mostrou a união em grupo como relata o aluno A5 afirmando os momentos de ajuda parecia que eles eram uma única pessoa, ou seja, com o mesmo objetivo de alcançar a aprendizagem dando seu melhor de modo a contribuir com a evolução do grupo. Como afirma Bacich, Neto e Trevisani (2015, p. 31),

aprendemos mais e melhor quando encontramos significado para aquilo que percebemos, somos e desejamos, quando há uma lógica nesse caminhar - no meio de inúmeras contradições e incertezas -, a qual ilumina nosso passado e presente, bem como orienta o futuro.

Motivar nossos alunos em seu íntimo é permiti-los alcançar inúmeras possibilidades do conhecimento, proporcionando a formação de alunos, éticos, ativos, participativos e consciente do seu papel social na medida em que desenvolve suas funções de construtores do futuro.

Diante das estratégias de coleta de dados utilizadas pelo pesquisador podemos observar a sintonia entre a análise dos dados com nossa fundamentação teórica, em especial, Onuchic e Allevato (2011) no qual relata que a partir da resolução de problemas o alunos coloca sua atenção na Matemática no momento em que faz-se sentido o conteúdo com suas vivências, utilizando diferentes possibilidades de estratégias de resolução dos problemas, verificando que cada indivíduo envolvido nesse processo pode percorrer caminhos diferentes, entretanto, ambos chegarão ao resultado satisfatório e a partir dessas estratégias de resoluções, tanto os professores como a instituição, possam buscar meios de proporcionar cada vez mais o envolvimento dos alunos no processo de aprendizagem da Matemática. 


\section{CONSIDERAÇÕES FINAIS}

O estudo aqui abordado proporcionou trabalharmos com o uso das metodologias ativas, em especial a $\mathrm{ABP}$, que teve como objetivo analisar, no contexto das aulas de Matemática do Ensino Fundamental, a possibilidade de se desenvolver práticas de aprendizagem de áreas de figuras planas, baseada em problemas.

A partir da convivência com os alunos participantes da pesquisa podemos observar uma prática educacional, com o uso das metodologias ativas para o ensino da geometria, em especial o ensino de áreas de uma figura plana, que envolve a participação dos alunos. Isso pode ser constatado a partir dos depoimentos dos alunos e o desejo em querer aprender e estarem dispostos aos desafios que estavam sendo propostos aos alunos desde a primeira etapa a última.

A participação dos envolvidos nesse processo de investigação foi um elemento fundamental para o desenvolvimento desse estudo, esse fator nos possibilitou reflexões e discursões a respeito do tema aqui apresentado. Isso só pode ser verificado a partir da observação do desejo dos alunos na construção do conhecimento, conhecimento que foi construído a partir da sua interação ativamente nas etapas desse estudo.

A partir dos questionamentos abordados e dos resultados apresentados, faz-se necessário pensarmos possibilidades de inovar nas aulas de Matemática de maneira a proporcionar aos alunos uma aprendizagem prazerosa, tornando cada vez mais o ensino da Matemática voltado para práticas pedagógicas inovadoras.

Na perspectiva apresentada é possível verificar as potencialidades das metodologias ativas e proporcionar aos professores a utilização desses recursos como forma de tornar suas aulas inovadores e atrativas, proporcionando aos seus alunos o desenvolvimento de alunos ativos e participativos na construção do conhecimento, reflexivos frente às diversas situações problemas que lhes possam ser apresentadas.

Os dados apresentados nesse estudo abordam uma perspectiva para educação matemática capaz de proporcionar aos estudantes o desenvolvimento do pensamento crítico e reflexivo, capaz de atuar em situações problemas do dia a dia na medida em que faz relação do conteúdo abordado em sala de aula com momentos vivenciados no seu cotidiano. 


\section{REFERÊNCIAS}

BACICH, L.; NETO, A. T.; TREVISANI, F. de M. (Orgs). Ensino Híbrido: personalização e tecnologia na educação. Porto Alegre: Penso, 2015.

BARROWS, H. S. TAMBLYN, R. M. Problem-Based Learning: Na Approach to Medical Education. Springer Publishing Company, New York, 1980.

BERGMANN, J.; SAMS, A. Sala de aula invertida: uma metodologia ativa de aprendizagem; tradução Afonso Celso da Cunha Serra. 1. Ed. Rio de Janeiro: LTC, 2018.

CARVAlHO, M. Problemas? Mas que problemas?!: estratégias de resolução de problemas matemáticos em sala de aula. $3^{\mathrm{a}}$ ed. Petrópolis, RJ: Vozes, 2010.

CLEMENTE, J. C. et al. Ensino e aprendizagem da geometria: um estudo a partir dos periódicos em educação matemática. ENCONTRO MINEIRO DE EDUCAÇÃO MATEMÁTICA, VII, 2015.

CRESWELL, J. W. Projeto de pesquisa: métodos qualitativos, quantitativos e misto / John W. Creswell; tradução Magda Lopes; consultoria, supervisão e revisão técnica desta edição Dirceu da Silva. - 3. ed. - Porto Alegre: Artmed, 2010.

FLICK, U. Introdução à pesquisa qualitativa. Tradução Joice Elias Costa. - 3. Ed. - Porto Alegre: Artmed, 2009.

GALVÃO, E. F. C.; GALVÃO, J. B. Pesquisa Intervenção e Análise Institucional: alguns apontamentos no âmbito da pesquisa qualitativa (2017). Disponível em: http://webcache.googleusercontent.com/search?q=cache:Vj9QBIyeDxsJ:www.ufopa.edu.b r/portaldeperiodicos/index.php/revistacienciasdasociedade/article/download/373/292+\&cd $=1 \& \mathrm{hl}=\mathrm{pt}-\mathrm{BR} \& \mathrm{ct}=\mathrm{clnk} \& \mathrm{gl}=\mathrm{br}$. Acesso em 16 de maio de 2020 .

JUNIOR, L. C. L.; ONUCHIC, L. de la R. Ensino e Aprendizagem de Matemática Através da Resolução de Problemas Como Prática Sociointeracionista. Bolema, Rio Claro (SP), v. 29, n. 53, p. 955-978, dez. 2015.

MUNHOZ, A. S. ABP: Aprendizagem Baseada em Problemas: ferramentas de apoio ao docente no processo de ensino e aprendizagem, São Paulo: Cengage Learning, 2018. ONUCHIC, L. de la R. Allevato, N. S. G. Pesquisa em Resolução de Problemas: caminhos, avanços e novas perspectivas (2011). Disponível em: 
https://intranet.ifs.ifsuldeminas.edu.br/antonio.gomes/3-7LM-TEM/onuchic\%2002-04-

19.pdf. Acesso em 16 de maio de 2020.

OLIVEIRA, C. A. da. Estratégias didáticas nos processos de ensino e de aprendizagem em matemática no mundo digital virtual em 3D Open Sim. 2015.

Tese (Doutorado). Doutorado em Educação, Universidade Federal de Alagoas, Maceió, 2015 .

PINHEIRO, M. S.; ANDRADE, M. E. de; JÚNIOR, R. L. C. de A. Descobrindo a aprendizagem baseada em problemas. Aracaju: EDUNIT, 2019.

RIBEIRO, L. R. de C. Aprendizagem Baseada em Problemas: uma experiência no ensino superior. São Carlos: EdUFSCar, 2010.

RIBEIRO, L. R. de C. A Aprendizagem baseada em problemas (PBL): Uma implementação na educação em engenharia na voz dos autores. 2005. Tese (Doutorado) Curso de Engenharia, Universidade Federal de São Carlos, São Carlos, 2005.

RIBEIRO, G. H. Aprendizagem Baseada em Problemas: metodologia inovadora no $9^{\circ}$ ano do ensino fundamental de uma escola pública. 2019. Dissertação (Mestrado) - PROFMAT, Universidade Federal de Goiás, 2019.

SAMPIERI, R. H.; COLLADO, C. F.; LUCIO, M. P. B. Metodologia de pesquisa. 5. ed. Porto Alegre: AMGH, 2013. 